\title{
Unprotected Galactosamine as a Dynamic Key for a Cyclochiral Lock
}

\author{
Caterina Fraschetti,* Matthias C. Letzel, Marlene Paletta, Jochen Mattay, Maria Elisa Crestoni, \\ Barbara Chiavarino, and Antonello Filippi
}

Cite This: https://dx.doi.org/10.1021/jasms.0c00437

ABSTRACT: The discrimination of D-galactosamine (G), representative of the amino-sugar class of compounds, has been probed through nano-ESI-FT-ICR mass spectrometry by isolating the relevant $[\mathbf{C} \cdot \mathbf{H} \cdot \mathbf{G}]^{+}$proton-bound complexes with the enantiomers of the cyclochiral resorcin[4]arene $\mathbf{C}$ and allowing them to react toward three primary amines $\left(\mathbf{B}=\mathrm{EtNH}_{2}, i \mathrm{PrNH}_{2}\right.$, and $(R)$ - and $\left.(S)-s \mathrm{BuNH}_{2}\right)$. The system under investigation presents several features that help to unveil the behavior of unprotected $\mathbf{G}$ in such a supramolecular architecture: (i) the hydrophobic derivatization of the $\mathbf{C}$ convex side forces the polar guest $\mathbf{G}$ to be coordinated by

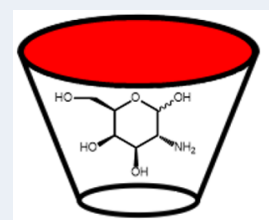

Gas-native

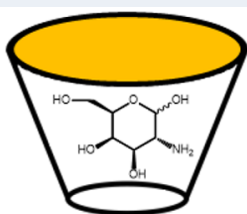

Solution-native

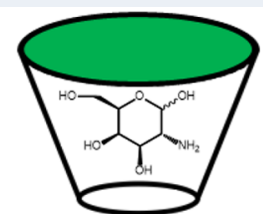

ESI-native

Reactivity the cyclochiral concave region; (ii) protonated D-galactosamine exists as an anomeric mixture, dynamically interconverting throughout the experimental time-window; and (iii) different basicities of B allow the experiment to subtly tune the reactivity of the $[\mathbf{C} \cdot \mathbf{H} \cdot \mathbf{G}]^{+}$complexes. Three $[\mathbf{C} \cdot \mathbf{H} \cdot \mathbf{G}]^{+}$aggregate-types were found to exist, differing in both their origin and reactivity. The most reactive adducts $\left([\mathbf{C} \cdot \mathrm{H} \cdot \mathbf{G}]_{\mathrm{ESI}}^{+}\right)$, generated in the electrospray environment, undergo a G-to-B ligand exchange in competition with a partial isomerization to the unreactive $[\mathbf{C} \cdot \mathrm{H} \cdot \mathbf{G}]_{\mathrm{GAS}}{ }^{+}$-type complexes. Finally, the poorly reactive $[\mathbf{C} \cdot \mathrm{H} \cdot \mathbf{G}]_{\mathrm{SOL}}{ }^{+}$aggregates are formed in solution over an hours-long time scale. A cyclochirality effect on the reactivity was found to depend on the considered $[\mathbf{C} \cdot \mathbf{H} \cdot \mathbf{G}]^{+}$aggregate-type.

\section{INTRODUCTION}

Over the last decades, supramolecular chemistry played a central role in a number of fields due to its impressive versatility in virtually any applied science. A suggestive, but not exhaustive, list of the most innovative applications ${ }^{1}$ includes the medical ones, ${ }^{2-7}$ especially molecular sensing and drug delivery, metal and ion-pair coordination, ${ }^{8-12}$ and anion recognition. ${ }^{13-16}$ The synthesis of any artificial receptor involves a size-specific design and a proper derivatization, which is finalized to optimize its molecular recognition ability. Among many other bioactive molecules, sugars and their derivatives constitute a class of compounds whose discrimination and sensing are particularly challenging, especially in water where host-guest interactions compete with solvation phenomena. Different efforts have very recently been devoted to discriminating between saccharides; pentoses have been extracted over hexose ${ }^{17}$ and their homo- and heterodimers were recognized through self-assembled double helical foldamers, ${ }^{18}$ non-all-equatorial saccharides were selected by "synthetic lectins", 19 oligosaccharides were distinguished by probing their length and building block compositions through specific nanoparticles, ${ }^{20}$ and $\beta$-glucoside was used as a reference carbohydrate for a series of synthetic receptors. ${ }^{21}$ Our research efforts, aimed at exploiting a highly directional noncovalent network to select saccharides, have been applied herein to their amino derivatives. Recently, an amphiphilic oligomer was found to form very stable complexes with D- glucosamine, ${ }^{22}$ but so far cucurbit[7]uril $(\mathrm{CB}[7])$ has been shown to be the best-suited receptor to discriminate between D-glucosamine and D-galactosamine by selectively trapping their $\alpha$-anomers. ${ }^{23}$ This very specific ability of $\mathrm{CB}[7]$ has been further investigated for analytical purposes by ESI-mass spectrometry, $^{24}$ whose speed and sensitivity are its most remarkable advantages. Interestingly, the $\alpha$-preference, highlighted in solution by NMR spectrocopy and confirmed in the solid state by single X-ray crystallography, is reversed when the relevant stability of the host-guest complexes is calculated in the gas phase. ${ }^{25}$ This study, providing the actual arrangement of the guest in the receptor cavity, points to the central role of water mediation in anomer discrimination. In particular, by only allowing the inclusion of several water molecules the binding free energy of the $\alpha-\mathrm{CB}[7]$ complex is lowered enough to invert the stability ranking in the gas phase.

Literature suffers from a significant lack of data concerning the amino-sugar discrimination in the gas phase where the solvent interference is suppressed and the noncovalent interactions network prevails, therefore driving the molecular

Received: December 1, 2020

Revised: January 13, 2021

Accepted: January 13, 2021 
recognition. In the present research, proton-bound complexes of D-galactosamine ( $\mathbf{G}$ ) were kinetically investigated in the gas phase through nano-ESI-FT-ICR, the mass spectrometry techniques of choice to gain experimental evidence about the features of gaseous noncovalent architectures. ${ }^{26,27}$ Resorcin[4]arenes are herein proposed as alternative cavities ${ }^{28-34}$ to selectively encapsulate unprotected amino-sugars. The high tunability of resorcin[4]arenes is due to the possibility of providing it with a chiral domain as a further stereospecific probe to induce guest-fitting. The following two chirality types can characterize the structure of a resorcin[4]arene: ${ }^{28}$ side chains in the down region or substituents on the upper-rim contain stereogenic centers (type 1) and achiral subunits that form a structurally chiral macrocyclic scaffold (type 2). Type 1 resorcin[4] arenes have been probed in the gas phase toward several chiral guests, i.e., peptides ${ }^{35}$ and nucleosides. ${ }^{36,37}$ The type 2 cyclochiral $\mathbf{C}$ resorcin[4] arene (Chart 1) has been

\section{Chart 1. Structures of $\mathrm{C}_{M, R}$}

and $\mathrm{C}_{P, S}$ Cyclochiral Resorcin[4]arenes
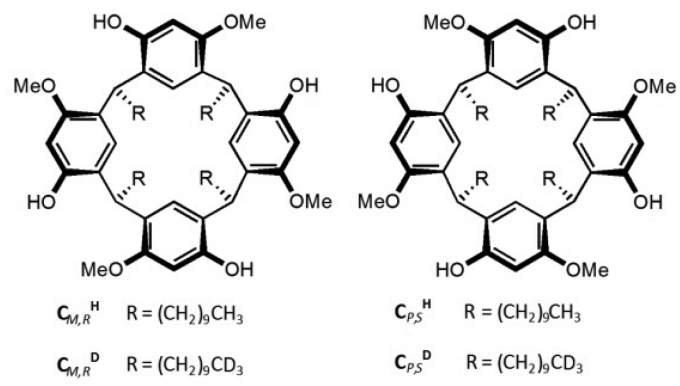

investigated toward a series of alcohols and amino-alcohols ${ }^{38}$ and showed a noticeable enantioselectivity, particularly in the complexes with amino-diols. Therefore, cyclochiral C resorcin[4] arene has been selected herein to be investigated as a potential receptor for D-galactosamine for the following two reasons: (i) its prominent selectivity for amino-alcohols induces us to assume a similar behavior toward D-galactosamine (Chart 2) and (ii) the presence of hydrophobic side chains should force a polar guest to interact with the chiral upper-rim by disadvantaging alternative arrangements.

The notations $(M, R)$ and $(P, S)\left(\mathbf{C}_{M, R}\right.$ and $\mathbf{C}_{P, S}$ in Chart 1$)$ refer to the axial asymmetry $(M$ and $P)$ and the configuration of the inter-ring carbons $(R$ and $S)$. Quasi-racemic $\mathbf{C}_{P, S} \mathbf{H}$ and $\mathbf{C}_{M, R}{ }^{\mathbf{D}}$ mixtures of the cyclochiral hosts (superscripts $\mathbf{H}$ and $\mathbf{D}$

Chart 2. ${ }^{1} \mathrm{C}_{4}$ and ${ }^{4} \mathrm{C}_{1}$ Chairs of Protonated D-Galactosamine $\alpha$ - and $\beta$-Anomers
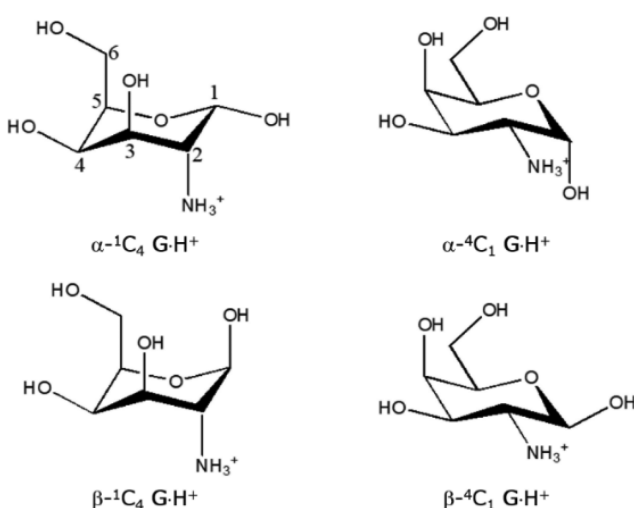

refer to the $-\mathrm{CH}_{3}$ and $-\mathrm{CD}_{3}$ terminals, respectively) were used to disentangle the kinetic results from any fluctuations of the nano-ESI conditions, thus enabling reactivity measurements of the corresponding quasi-diastereomeric complexes (i.e., $\left[\mathbf{C}_{P, S}{ }^{\mathbf{H}}\right.$. $\mathbf{H} \cdot \mathbf{G}]^{+}$and $\left[\mathbf{C}_{M, R}{ }^{\mathbf{D}} \cdot \mathbf{H} \cdot \mathbf{G}\right]^{+}$) in the same mass spectrometry environment. ${ }^{39}$ The gas-phase reactivity of $[\mathbf{C} \cdot \mathbf{H} \cdot \mathbf{G}]^{+}$aggregates was measured toward the following primary amines (B) to tune the ligand-exchange reactivity (eq 1a) and test the selectivity of different basic neutral reagents: $\mathrm{EtNH}_{2}, i \mathrm{PrNH}_{2}$, and $(R)$ - and $(S)-s \mathrm{BuNH}_{2}$.

$$
\begin{aligned}
& {\left[\mathbf{C}_{P, S}^{\mathbf{H}} \cdot \mathbf{H} \cdot \mathbf{G}\right]^{+}+\mathrm{B} \rightarrow\left[\mathbf{C}_{P, S}^{\mathbf{H}} \cdot \mathrm{H} \cdot \mathbf{B}\right]^{+}+\mathbf{G}} \\
& {\left[\mathbf{C}_{M, R}^{\mathbf{D}} \cdot \mathrm{H} \cdot \mathbf{G}\right]^{+}+\mathbf{B} \rightarrow\left[\mathrm{C}_{M, R}^{\mathbf{D}} \cdot \mathrm{H} \cdot \mathbf{B}\right]^{+}+\mathbf{G}}
\end{aligned}
$$

Because of the aptitude of $\mathbf{G}$ to anomerize, the kinetics experiments were performed on both the fresh solutions $\left(t_{0 \mathrm{~h}}\right.$ data) and after $24 \mathrm{~h}$ ( $t_{24 \mathrm{~h}}$ data) according to the procedure described in the following section.

\section{EXPERIMENTAL SECTION}

Materials. The synthesis, purification, and characterization of the $\mathbf{C}_{P, S}{ }^{\mathbf{D}} / \mathbf{C}_{M, R} \mathbf{D}$ and $\mathbf{C}_{P, S} \mathbf{H} / \mathbf{C}_{M, R}{ }^{\mathbf{H}}$ racemates were previously reported. $^{38} \mathrm{D}-(+)$-Galactosamine hydrochloride, $\mathrm{EtNH}_{2}$, $i \mathrm{PrNH}_{2}$, and $(R)$ - and $(S)-s \mathrm{BuNH}_{2}$ have been purchased from a commercial source.

ESI-FT-ICR Experiments. The kinetic measurements were performed at room temperature in an APEX III 7.0 T FT-ICR mass spectrometer (Bruker Daltonic $\mathrm{GmbH}$, Bremen) fitted with a nano-ESI source (Apollo) and a resonance cell. An equimolar mixture of the quasi-enantiomer hosts $\mathbf{C}_{P, S}{ }^{\mathbf{H}}$ and $\mathrm{C}_{M, R}{ }^{\mathrm{D}}$ was dissolved in $\mathrm{CH}_{3} \mathrm{OH} / \mathrm{CHCl}_{3}(10: 1)$ up to a final $10^{-5} \mathrm{M}$ concentration and mixed with $6 \times 10^{-5} \mathrm{M} \mathrm{D}$ $(+)$-galactosamine to prepare fresh solutions that were ready to be promptly analyzed ( $t_{0 \mathrm{~h}}$ solutions). The coexistence of the deuterated host ensured an identical experimental environment for the quasi-diastereoisomer complexes in both the solution and the gas phase. The aging effect was evaluated by reanalyzing the same solutions after $24 \mathrm{~h}$ of storage at room temperature $\left(t_{24 \mathrm{~h}}\right.$ solutions). The ions coming from the ion source were accumulated in a hexapole and transferred into the resonance cell through a system of potentials and lenses. Finally, the ions were cooled by collisions with argon, which was pulsed into the cell through a magnetic valve. The mass spectra of both the $t_{0 \mathrm{~h}}$ and $t_{24 \mathrm{~h}}$ electrosprayed solutions substantially showed the exclusive presence of two signals with same intensities that corresponded to the $\left[\mathbf{C}^{\mathrm{H}} \cdot \mathbf{H} \cdot \mathbf{G}\right]^{+}$and $\left[\mathbf{C}^{\mathbf{D}}\right.$. $\mathrm{H} \cdot \mathbf{G}]^{+}$proton-bound complexes. Each signal was isolated by the broad-band ejection of the accompanying minor ions and allowed to react with a neutral gas $\mathbf{B}$ present in the cell at a controlled pressure (ranging from $2.0 \times 10^{-9}$ to $4.5 \times 10^{-8}$ mbar depending upon their reactivity). The occurrence of any isotopic effect was evaluated by calculating the relevant $\mathrm{KIE}$ ratios $\left(\mathrm{KIE}=k \mathrm{C}_{P, S}{ }^{\mathrm{H}} / k \mathrm{C}_{P, S} \mathrm{D}\right.$ and $\left.\mathrm{KIE}=k \mathrm{C}_{M, R}{ }^{\mathrm{H}} / k \mathrm{C}_{M, R}{ }^{\mathrm{D}}\right)$. The effect of the resorcinarene cyclochirality was calculated through the $\rho=k \mathbf{C}_{P, S} / k \mathbf{C}_{M, R}$ ratio, where $k \mathbf{C}_{P, S}$ and $k \mathbf{C}_{M, R}$ refer to the rate constants measured with the $\mathbf{C}_{P, S}{ }^{\mathbf{H}}$ and $\mathbf{C}_{M, R}{ }^{\mathbf{D}}$ hosts (alternatively the $\mathbf{C}_{P, S}{ }^{\mathbf{D}}$ and $\mathbf{C}_{M, R}{ }^{\mathbf{H}}$ hosts), respectively. Finally, the effect of the chiral amine configuration $\left((R)-\sec -\mathrm{BuNH}_{2}=\right.$ $k_{(R)}$ vs $(S)$-sec- $\left.\mathrm{BuNH}_{2}=k_{(S)}\right)$ on the reactions was inferred from the relevant $\xi=k_{(R)} / k_{(S)}$ ratio. It should be underlined that the enantioselectivity and thus the $s \mathrm{BuNH}_{2}$ chirality effect increases as the $\rho$ and $\xi$ ratios, respectively, diverge from unity. 
No appreciable deviation of $\rho$ from unity was obtained in the control experiments performed using glycine ethyl ester $(\mathbf{L})$ as an achiral guest $\left(\left[\mathbf{C}_{P, S}{ }^{\mathbf{H}} \cdot \mathbf{H} \cdot \mathbf{L}\right]^{+} /\left[\mathbf{C}_{M, R}{ }_{\mathrm{D}} \cdot \mathbf{H} \cdot \mathbf{L}\right]^{+} \rho=0.98 \pm 0.06\right.$ and $\left.\left[\mathbf{C}_{P, S}{ }^{\mathrm{D}} \cdot \mathbf{H} \cdot \mathbf{L}\right]^{+} /\left[\mathbf{C}_{M, R}{ }^{\mathrm{H}} \cdot \mathbf{H} \cdot \mathbf{L}\right]^{+} \rho=1.00 \pm 0.06\right)$ in the reaction toward $(R)$-sec-butylamine. Each kinetic measurement was performed in triplicate. Kinetic data were processed by plotting the $[\mathbf{C} \cdot \mathbf{H} \cdot \mathbf{G}]_{t}^{+} /[\mathbf{C} \cdot \mathbf{H} \cdot \mathbf{G}]_{0}^{+}$ratio versus the reaction time, wherein $[\mathbf{C} \cdot \mathbf{H} \cdot \mathbf{G}]_{t}^{+}$was the precursor abundance at the reaction time $t$ and $[\mathbf{C} \cdot \mathbf{H} \cdot \mathbf{G}]_{0}^{+}$was the sum of the residual $[\mathbf{C}$. $\mathbf{H} \cdot \mathbf{G}]_{t}^{+}$and the $[\mathbf{C} \cdot \mathbf{H} \cdot \mathbf{B}]_{t}^{+}$product ion. The best-fit of the $[\mathbf{C}$. $\mathbf{H} \cdot \mathbf{G}]_{t}^{+} /[\mathbf{C} \cdot \mathbf{H} \cdot \mathbf{G}]_{0}^{+}$ratio versus time provided the corresponding pseudo-first-order rate constants $\left(k^{\prime}\right)$ of eqs la-b. A monoexponential decay of the precursor ion indicates that either only one reacting species is present or more than one reacting species is present, all of which have very similar rate constants. Instead, when the precursor ion was isolated as a mixture of isomers reacting with two distinguishable rate constants, a biexponential decay was recorded (Scheme 1a). A

Scheme 1. (a) Biexponential and (b) Parallel Kinetic Schemes for the Reaction of $[\mathrm{C} \cdot \mathrm{H} \cdot \mathrm{G}]^{+}$Complexes with a Neutral Gas B

a)

$$
\begin{aligned}
& {[\mathrm{C} \cdot \mathrm{H} \cdot \mathrm{G}]_{\text {fast }}+\underset{k_{\text {fast }}}{\stackrel{+\mathrm{B}}{\longrightarrow}}[\mathrm{C} \cdot \mathrm{H} \cdot \mathrm{B}]^{+}+\mathbf{G}} \\
& {[\mathrm{C} \cdot \mathrm{H} \cdot \mathrm{G}]_{\text {slow }}+\underset{k_{\text {slow }}}{\stackrel{+\mathrm{B}}{\longrightarrow}}[\mathrm{C} \cdot \mathrm{H} \cdot \mathrm{B}]^{+}+\mathbf{G}}
\end{aligned}
$$

b)

$$
\begin{array}{r}
k_{\mathrm{obs}}=k_{\mathrm{s}}+k_{\text {iso }} \\
{[\mathrm{C} \cdot \mathrm{H} \cdot \mathrm{G}]+\underset{k_{\text {iso }}}{\longrightarrow}[\mathrm{C} \cdot \mathrm{H} \cdot \mathrm{G}]_{\mathrm{GAS}^{+}}} \\
\stackrel{k_{\mathrm{sbs}}}{\longrightarrow}[\mathrm{C} \cdot \mathrm{H} \cdot \mathrm{B}]^{+}+\mathrm{G}
\end{array}
$$

biexponential best-fitting provided two pseudo-first-order rate constants (i.e., "fast" and "slow") and the relative amount of the $[\mathbf{C} \cdot \mathbf{H} \cdot \mathbf{G}]^{+}$reactive populations (Scheme $\left.1 \mathrm{a}\right){ }^{28}$ It is worth noting that in pure biexponential kinetics the relative abundance of the "fast" and "slow" populations do not depend on the nature of the neutral gas $\mathbf{B}$. On the contrary, if the amount of the extrapolated populations changes with $\mathbf{B}$, a gasphase isomerization of the $[\mathbf{C} \cdot \mathbf{H} \cdot \mathbf{G}]^{+}$species can be assumed to take place in competition with the ligand exchange reactions (Scheme 1b).

\section{RESULTS}

The $t_{0 \mathrm{~h}}$ kinetic plots obtained in the reactions toward $\mathbf{B}=$ $\mathrm{EtNH}_{2}$ and $i \mathrm{PrNH}_{2}$ reach plateau (Supporting Information Figures $\mathrm{S} 1-\mathrm{S} 4$ ) whose values clearly decrease as the proton affinity of $\mathbf{B}\left(\mathrm{PA}_{\mathbf{B}}\right)$ increases, eventually becoming undetectable when $\mathbf{B}=s \mathrm{BuNH}_{2}$ (Figures S5 and $\mathrm{S} 6 ; \mathrm{PA}_{\mathbf{B}}{ }^{40}$ in kilojoules per mole: $\mathrm{EtNH}_{2}=912$; $i \mathrm{PrNH}_{2}=923.8$; and $s \mathrm{BuNH}_{2}=$ 929.7).

The $t_{0 \mathrm{~h}}$ raw data were subjected to best-fitting procedures according to several kinetics models (vide infra). The results can be summarized as follows: (i) a monoexponential model is exclusively the best-fit for the reactivity of the $[\mathbf{C} \cdot \mathbf{H} \cdot \mathbf{G}]^{+}$ complexes toward $\mathbf{B}=s \mathrm{BuNH}_{2}$ (Figures S7 and S8); (ii) given that a plateau inherently indicates the existence of nonreactive populations, a monoexponential scheme summed to a constant abundance of an unreactive species was successfully applied to best-fit the raw data for $\mathbf{B}=i \operatorname{PrNH}_{2}$, but worse results were obtained when $\mathbf{B}=\mathrm{EtNH}_{2}$; (iii) a biexponential scheme in the presence of a constant nonreactive complex fits the raw data for $\mathbf{B}=\mathrm{EtNH}_{2}$ well. Nevertheless, the $\mathrm{PA}_{\mathbf{B}}$ dependences of $16-21 \%$ and 5.0-6.0\%, when $\mathbf{B}=\mathrm{EtNH}_{2}$ and $i \mathrm{PrNH}_{2}$, respectively, of the plateau positions (Figures S1S4) are in contrast with a kinetic scheme involving a constant amount of the unreactive population. As already mentioned in the previous section, the $\mathrm{PA}_{\mathrm{B}}$ dependence of the plateau can be explained using the simpler alternative to Scheme 1a, i.e., Scheme $1 \mathrm{~b}$, in which the isomeric (and unreactive) $[\mathrm{C} \cdot \mathrm{H}$. $\mathbf{G}]_{\mathrm{GAS}^{+}}$species is formed as a consequence of the gas-phase rearrangement of the "native" $[\mathbf{C} \cdot \mathbf{H} \cdot \mathbf{G}]^{+}$isolated ion in competition with the direct ligand-exchange reactions (1). Fitting the raw data first required the determination of the actual reactive fraction of the precursor ion, which was cleaned up from the unreactive $[\mathbf{C} \cdot \mathbf{H} \cdot \mathbf{G}]_{\mathrm{GAS}}{ }^{+}$isomer that was formed throughout the experiment. According to the Scheme 2a, the

Scheme 2. Parallel Kinetic Schemes of (a) $[\mathrm{C} \cdot \mathrm{H} \cdot \mathrm{G}]_{\mathrm{fast}-0}{ }^{+}(\mathrm{B}$ $\left.=i \operatorname{PrNH}_{2}\right)$ and $(\mathrm{b})[\mathrm{C} \cdot \mathrm{H} \cdot \mathrm{G}]_{\text {fast }-0}{ }^{+}$and $[\mathrm{C} \cdot \mathrm{H} \cdot \mathrm{G}]_{\text {slow }-0}{ }^{+}$ complexes $\left(\mathrm{B}=\mathrm{EtNH}_{2}\right)$ at $t_{0 \mathrm{~h}}$

a)

$k_{\mathrm{obs}}=k_{\mathrm{s}}+k_{\text {iso }}$

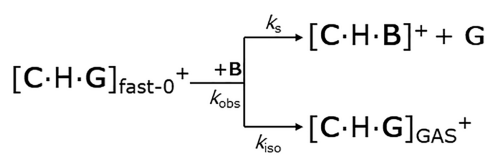

b)

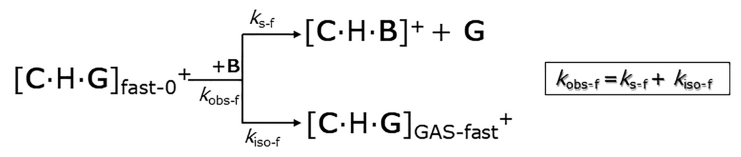

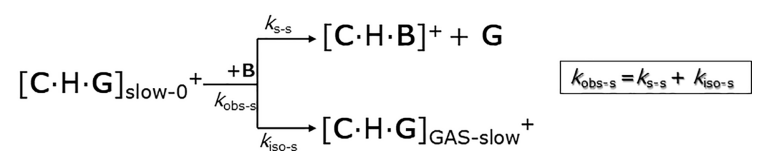

$[\mathbf{C} \cdot \mathbf{H} \cdot \mathbf{B}]^{+}$and $[\mathbf{C} \cdot \mathbf{H} \cdot \mathbf{G}]_{\mathrm{GAS}^{+}}$abundances measured after reaching the plateau provide the $k_{\mathrm{s}} / k_{\text {iso }}$ ratio (eq 2); therefore, the eq 2 can be applied to determine $[\mathbf{C} \cdot \mathbf{H} \cdot \mathbf{G}]_{\mathrm{GAS}^{+}}$at any time $t$

$$
\frac{k_{\mathrm{s}}}{k_{\mathrm{iso}}}=\frac{[\mathbf{C} \cdot \mathrm{H} \cdot \mathbf{B}]^{+}}{[\mathbf{C} \cdot \mathrm{H} \cdot \mathbf{G}]_{\mathrm{GAS}}^{+}}
$$

Then, if the $[\mathbf{C} \cdot \mathbf{H} \cdot \mathbf{G}]_{\mathrm{GAS}^{+}}{ }^{+}$is subtracted from the isolated $[\mathbf{C}$. $\mathrm{H} \cdot \mathbf{G}]^{+}$ion at any time $t$, the actual reactive fraction of the precursor can be obtained; the logarithmic plots are reported in Figures S9-S12. A single monoexponential decay $\left(k_{\mathrm{s}}\right)$ in competition with an isomerization reaction ( $k_{\text {iso; }}$ Scheme $2 \mathrm{a}$ ) fits the $\mathbf{B}=i \mathrm{PrNH}_{2}$ data very well (Figures S11-S12) but not the $\mathbf{B}=\mathrm{EtNH}_{2}$ data. Indeed, the logarithmic plot of the $\left[\mathbf{C}_{P, S}{ }^{\mathbf{H}}\right.$. $\mathrm{H} \cdot \mathbf{G}]^{+}$complex presents a slight deviation from linearity (Figure S9) that is much more evident when the $\left[\mathbf{C}_{M, R}{ }^{\mathbf{D}} \cdot \mathbf{H} \cdot \mathbf{G}\right]^{+}$ ion is considered (Figure S10). Such behavior points to the existence of two "native" reactive $[\mathbf{C} \cdot \mathbf{H} \cdot \mathbf{G}]^{+}$species, namely $[\mathbf{C} \cdot \mathbf{H} \cdot \mathbf{G}]_{\text {fast }-0^{+}}{ }^{+}$and $[\mathbf{C} \cdot \mathbf{H} \cdot \mathbf{G}]_{\text {slow }-0}{ }^{+}$, that are not discriminated by $i \mathrm{PrNH}_{2}$ (Figures S11 and S12 show the linear plots), both of 

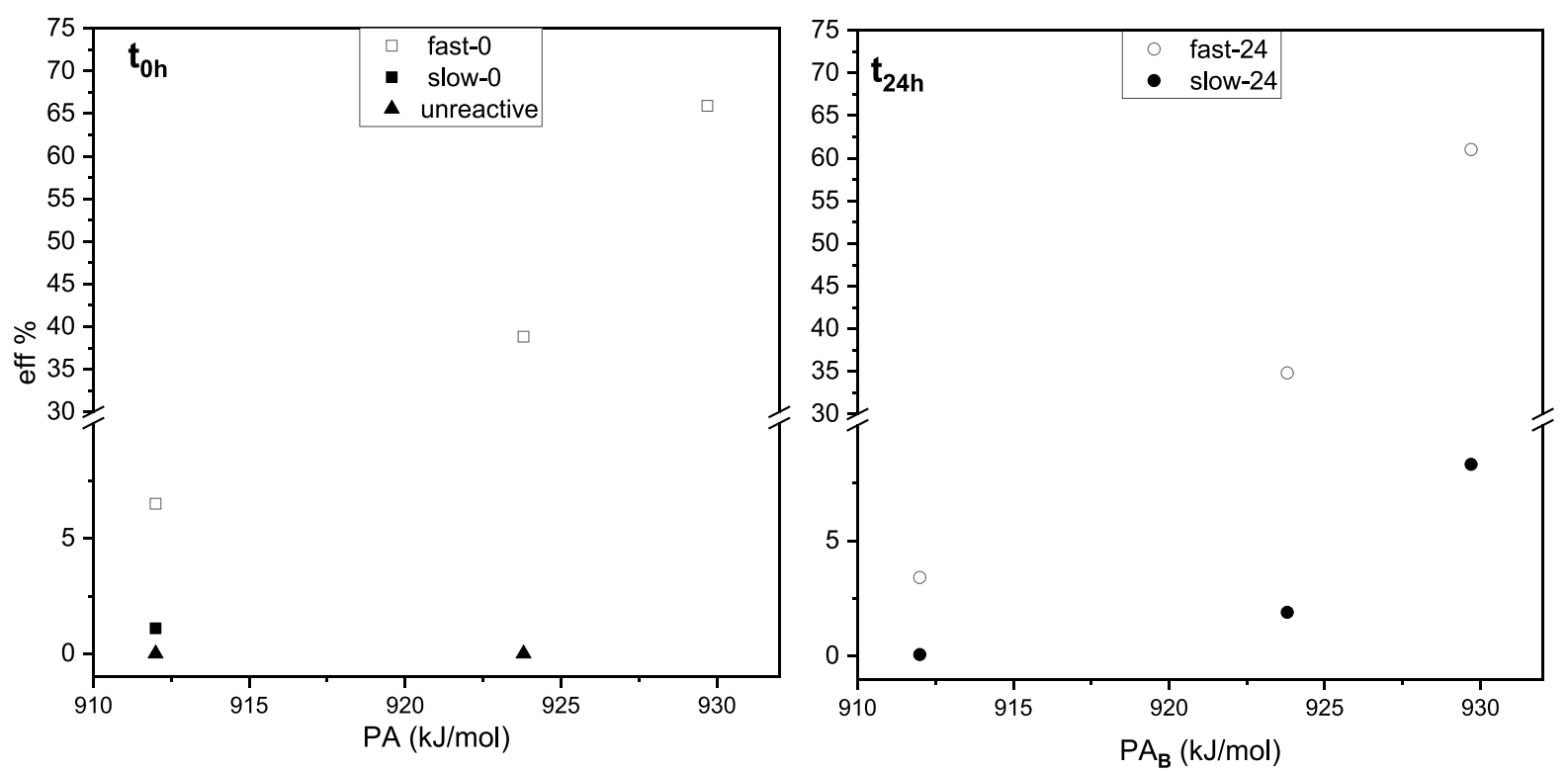

Figure 1. Reaction efficiency percentages of $\left[\mathbf{C}_{P, S}{ }^{\mathrm{H}} \cdot \mathbf{H} \cdot \mathbf{G}\right]^{+}$ions vs the proton affinity of the neutral gas $\mathbf{B}$ in the $t_{0 \mathrm{~h}}($ left $)$ and $t_{24 \mathrm{~h}}($ right) experiments.

which in principle can isomerize to the relevant unreactive [C. $\mathrm{H} \cdot \mathbf{G}]_{\mathrm{GAS}}{ }^{+}$species $\left(k_{\text {iso-f }}\right.$ and $k_{\text {iso-s }}$, respectively, in Scheme $2 \mathrm{~b}$ ) in competition with the corresponding ligand-exchange reaction $\left(k_{s-f}\right.$ and $k_{s-s}$, respectively). Quite surprisingly, the kinetics of the same solutions reanalyzed after $24 \mathrm{~h}\left(t_{24 \mathrm{~h}}\right)$ were extremely different (Figures S13-S18), being much slower than the corresponding $t_{0 \mathrm{~h}}$ kinetics. Moreover, the assessment of a plateau in the experimental plots of $\mathbf{B}=i \mathrm{PrNH}_{2}$ and $s \mathrm{BuNH}_{2}$ is arduous (Figures S15-S18) if not impossible when $\mathbf{B}=\mathrm{EtNH}_{2}$ (Figures S13-S14) as a result of the extremely poor reactivity of the predominant slow- 24 components. It follows that the nature of the $[\mathbf{C} \cdot \mathbf{H} \cdot \mathbf{G}]^{+}$complexes is different in the $t_{0 \mathrm{~h}}$ and $t_{24 \mathrm{~h}}$ experiments and the formation of possibly minor fractions of any unreactive $[\mathbf{C} \cdot \mathbf{H} \cdot \mathbf{G}]_{\mathrm{GAS}}{ }^{+}$species cannot be revealed in the $t_{24 \mathrm{~h}}$ experiments. However, irrespective of the nature of $\mathbf{B}$, all the $t_{24 \mathrm{~h}}$ raw data (Figures S13-S18) fit a biexponential decay (Scheme 1a).

The second-order constants $k$ were calculated as $k=k^{\prime} /[\mathbf{B}]$ from the pseudo-first-order rate constants $\left(k^{\prime}\right)$, and the relevant reaction efficiencies determined as eff $=100 k / k_{\text {cap }}$ $\left(k_{\text {cap }}\right.$ is the thermal capture collision rate ${ }^{41,42}$ ) are listed in Tables S1-S3 for both $t_{0 \mathrm{~h}}$ and $t_{24 \mathrm{~h}}$ data. Note that best-fit of the $t_{0 \mathrm{~h}}$ experimental data allowed us to calculate either the ligand exchange $\left(k_{\mathrm{s}}\right)$ or the isomerization $\left(k_{\text {iso }}\right)$ rate constants in the reactions toward $i \mathrm{PrNH}_{2}$ (Scheme 2a) where only one reacting population was detected $\left([\mathbf{C} \cdot \mathbf{H} \cdot \mathbf{G}]_{\text {fast }-0}\right.$ in Scheme $2 \mathrm{a}$ and Table S2). However, discriminating between two reacting complexes in the reaction with $\mathrm{EtNH}_{2}\left([\mathbf{C} \cdot \mathrm{H} \cdot \mathbf{G}]_{\text {fast-0 }}{ }^{+}\right.$and $[\mathbf{C}$. $\mathrm{H} \cdot \mathbf{G}]_{\text {slow }-0}{ }^{+}$in Scheme $2 \mathrm{~b}$ and Table S1) makes the system mathematically unsolvable. Indeed, Table $S 1$ (the $t_{0 \mathrm{~h}}$ solution) reports values of $k_{\mathrm{obs}}$ as the sum of the substitution $\left(k_{\mathrm{s}}\right)$ and the isomerization $\left(k_{\text {iso }}\right)$ rate constants. Taking into account that the experimental uncertainty actually does not exceed $\pm 10 \%$, the calculated KIE values (Table S4) confirm that the observed reactions are basically not affected by any significant isotope effects; therefore, only the $\left[\mathbf{C}_{P, S}{ }^{\mathrm{H}} \cdot \mathbf{H} \cdot \mathbf{G}\right]^{+} /\left[\mathbf{C}_{M, R} \mathbf{D} \cdot \mathbf{H} \cdot \mathbf{G}\right]^{+}$pair will be discussed further below.

\section{DISCUSSION}

Figure 1 reports the reaction percent efficiency of $\left[\mathbf{C}_{P, S}{ }^{\mathrm{H}} \cdot \mathbf{H} \cdot \mathbf{G}\right]^{+}$ (see Figure S19 for eff \% values of the $\left[\mathbf{C}_{M, R} \mathbf{D} \cdot \mathbf{H} \cdot \mathbf{G}\right]^{+}$quasidiastereoisomer) vs $\mathrm{PA}_{\mathrm{B}}$ (for convenience, values measured for the reaction toward the R-enantiomer of $s \mathrm{BuNH}_{2}$ are reported, the base chirality effect being discussed further down).

In general, the reactivity increases with $\mathrm{PA}_{\mathrm{B}}$ whereas the ability to discriminate different kinetic populations follows the opposite trend at $t_{0 \mathrm{~h}}$. Indeed, the less reactive $\mathrm{EtNH}_{2}$ discriminates two distinct aggregates (namely $[\mathbf{C} \cdot \mathbf{H} \cdot \mathbf{G}]_{\text {fast }-0^{+}}$ and $[\mathbf{C} \cdot \mathbf{H} \cdot \mathbf{G}]_{\text {slow-0 }}{ }^{+}$) undergoing a ligand exchange in competition with a gas-phase isomerization to the unreactive $[\mathbf{C} \cdot \mathrm{H} \cdot \mathbf{G}]_{\mathrm{GAS}}{ }^{+}$adduct (Scheme $\left.2 \mathrm{~b}\right)$. More basic $i \mathrm{PrNH}_{2}$ kinetically discriminates just one reactive population $([\mathrm{C} \cdot \mathrm{H} \cdot$ $\left.\mathbf{G}]_{\text {fast-0 }}{ }^{+}\right)$, undergoing either ligand exchange and isomerization to the nonreactive $[\mathbf{C} \cdot \mathrm{H} \cdot \mathbf{G}]_{\mathrm{GAS}}{ }^{+}$species (Scheme 2a). Finally, a single reactive population $\left([\mathbf{C} \cdot \mathrm{H} \cdot \mathbf{G}]_{\mathrm{fast}_{-0}}{ }^{+}\right)$is detected, exclusively undergoing a ligand exchange reaction, when the ICR-cell is loaded with the most basic $s \mathrm{BuNH}_{2}$. As stated before, the final abundance of the unreactive population (i.e., the extent of isomerization) in the $t_{0 \mathrm{~h}}$ solutions shows a clear trend with $\mathrm{PA}_{\mathbf{B}}$ (Figures $\mathrm{S} 1-\mathrm{S} 3$ and Table 1); it goes from about 21-16\% $\left(\mathbf{B}=\mathrm{EtNH}_{2}\right)$, passes through $6.0-5.0 \%(\mathbf{B}=$ $i \operatorname{PrNH}_{2}$ ), and is finally undetectable when $\mathbf{B}=s \mathrm{BuNH}_{2}$. Such a $\mathrm{PA}_{\mathrm{B}}$ dependence agrees with an isomerization of the native [C. $\mathrm{H} \cdot \mathbf{G}]^{+}$complexes being catalyzed by the neutral $\mathbf{B}$ gas and yielding a more stable, and unreactive, supramolecular architecture (e.g., $[\mathbf{C} \cdot \mathbf{H} \cdot \mathbf{G}]_{\mathrm{GAS}^{+}}{ }^{+}$). In other words, B plays a double role: the collisions occurring in the cell promote a ligand exchange in competition with unreactive events that in turn deposit enough energy to trigger intracomplex isomerization.

Concerning the $t_{24 \mathrm{~h}}$ experiments, $[\mathbf{C} \cdot \mathrm{H} \cdot \mathbf{G}]^{+}$complexes invariably obey a biexponential decay (Scheme 1a), with efficiency values increasing with the $\mathrm{PA}_{\mathrm{B}}$ for both the fast-24 and the slow-24 reactions (Figure 1). It is noteworthy that the efficiencies of the fast-24 aggregates are very close to those of the corresponding fast- 0 for $\mathbf{B}=i \mathrm{PrNH}_{2}$ and $s \mathrm{BuNH}_{2}$ and are intermediate between fast- 0 and slow- 0 for $\mathbf{B}=\mathrm{EtNH}_{2}$ (Figure 
Table 1. Fast and Slow Populations Percentage Distribution for the Reaction of the $\left[\mathrm{C}_{P, S} \mathrm{H} \cdot \mathrm{H} \cdot \mathrm{G}\right]^{+}$and $\left[\mathrm{C}_{M, R}{ }^{\mathrm{D}} \cdot \mathrm{H} \cdot \mathrm{G}\right]^{+}$ Complexes vs the Neutral Gases $B$

\begin{tabular}{|c|c|c|c|c|c|c|c|c|}
\hline \multicolumn{9}{|c|}{$t_{0 \mathrm{~h}}$ solution } \\
\hline \multirow[b]{2}{*}{ host } & \multicolumn{3}{|c|}{$\mathbf{B}=\mathrm{EtNH}_{2}$} & \multicolumn{3}{|c|}{$\mathbf{B}=i \mathrm{PrNH}_{2}$} & \multicolumn{2}{|c|}{$\mathbf{B}=s \mathrm{BuNH}_{2}$} \\
\hline & fast -0 & slow-0 & unreactive $^{a}$ & fast-0 & unrea & $\mathrm{ive}^{a}$ & \multicolumn{2}{|c|}{ fast- 0} \\
\hline $\mathbf{C}_{P, S}{ }^{\mathbf{H}}$ & 19 & 81 & 21 & 100 & \multicolumn{2}{|c|}{6.0} & \multicolumn{2}{|c|}{100} \\
\hline $\mathrm{C}_{M, R} \mathbf{D}$ & 44 & 56 & 16 & 100 & \multicolumn{2}{|c|}{5.0} & \multicolumn{2}{|c|}{100} \\
\hline \multicolumn{9}{|c|}{$t_{24 \mathrm{~h}}$ solution } \\
\hline & \multicolumn{2}{|c|}{$\mathbf{B}=\mathrm{EtNH}_{2}$} & \multicolumn{2}{|c|}{$\mathbf{B}=i \mathrm{PrNH}_{2}$} & \multicolumn{4}{|c|}{$\mathbf{B}=s \mathrm{BuNH}_{2}$} \\
\hline & fast-24 & slow- 24 & fast-24 & slow-24 & & & slo & \\
\hline host & & & & & $R$ & $S$ & $R$ & $S$ \\
\hline $\mathbf{C}_{P, S}{ }^{\mathbf{H}}$ & 24 & 76 & 35 & 65 & 38 & 45 & 62 & 55 \\
\hline $\mathbf{C}_{M, R}{ }^{\mathbf{D}}$ & 16 & 84 & 27 & 73 & 29 & 36 & 71 & 64 \\
\hline
\end{tabular}

${ }^{a}$ Indicates the final abundance of the unreactive species (i.e., the position of the plateau). The uncertainty of the reported values does not exceed $5 \%$.

1 and S19). On the contrary, slow-24 components were not revealed at all in the $t_{0 \mathrm{~h}}$ experiments. This multifaceted landscape raises the first issue concerning the origin of the complexes we are looking at. According to previous evidence, ${ }^{38}$ in the fresh solution ( $t_{0 \mathrm{~h}}$ experiments) the poorly polar $\mathbf{C}$ resorcin[4] arene substantially coordinates a polar guest during the electrospray process to form the proton-bound aggregates under investigation. Furthermore, the ESI-formed complexes of $\mathbf{C}$ and several tested amino-alcohols exist as a single kinetic structure, as indicated by the exclusive occurrence of monoexponential depletions. ${ }^{38}$ Nevertheless, the $\alpha / \beta$-distribution of the free protonated galactosamine measured in solution changes within $24 \mathrm{~h}^{43}\left(\alpha / \beta=3 / 97\right.$ and $19 / 81$ for the $t_{0 \mathrm{~h}}$ and $t_{24 \mathrm{~h}}$ solutions, respectively); however, the $\alpha \leftrightarrows \beta$ anomerization is catalyzed under ESI conditions, leading to larger electrospray $\alpha / \beta$-ratios $\left(\alpha / \beta=36 / 64\right.$ and $75 / 25$ for the $t_{0 \mathrm{~h}}$ and $t_{24 \mathrm{~h}}$ solutions, respectively). ${ }^{43}$ Such evidence indicates that in the present study the cyclochiral receptor $\mathbf{C}$ deals with anomeric dynamically evolving mixtures. If the same $[\mathbf{C} \cdot \mathbf{H} \cdot \alpha-\mathbf{G}]^{+}$and $[\mathbf{C} \cdot \mathrm{H} \cdot \beta-\mathbf{G}]^{+}$aggregates would be involved over all the experiments, the $t_{0 \mathrm{~h}}$ and $t_{24 \mathrm{~h}}$ kinetics toward any given base B should differ from each other by only the relative amount of the reacting adducts (reflecting to some extent the different relative amounts of $\alpha$ - and $\beta$-anomers of galactosamine) and not the rate constants. As this is not the case (Tables S1-S3), the presence of different aggregate types has to be assumed. The substantial similarity between the fast- 24 efficiencies and both the fast-0 (all-B) and slow-0 $\left(\mathbf{B}=\mathrm{EtNH}_{2}\right)$ efficiencies (Figures 1 and S19) points to the existence of an aggregate type that is formed in the electrospray ionization process (hereafter tagged as $[\mathbf{C} \cdot \mathrm{H} \cdot \mathbf{G}]_{\mathrm{ESI}}$ ) in both the $t_{0 \mathrm{~h}}$ and $t_{24 \mathrm{~h}}$ experiments. On the other side, the slow-24 fraction (hereafter tagged as $\left.[\mathbf{C} \cdot \mathrm{H} \cdot \mathbf{G}]_{\mathrm{SOL}}{ }^{+}\right)$that is absent in the $t_{0 \mathrm{~h}}$ experiments has to be formed in solution over a longer time scale. Moreover, the fast-24 (i.e., $[\mathbf{C} \cdot \mathrm{H} \cdot \mathbf{G}]_{\mathrm{ESI}}{ }^{+}$) abundance slightly decreases as the $\mathrm{PA}_{\mathbf{B}}$ decreases (Table 1), which is in agreement with the occurrence of $[\mathbf{C} \cdot \mathrm{H} \cdot \mathbf{G}]_{\mathrm{ESI}}{ }^{+} \rightarrow[\mathbf{C} \cdot \mathrm{H} \cdot$ $\mathbf{G}]_{\mathrm{GAS}^{+}}{ }^{+}$interconversion that is the more extensive with the less efficient $\mathbf{B}\left(\mathrm{EtNH}_{2}\right)$. However, the question arises as to why the $[\mathbf{C} \cdot \mathbf{H} \cdot \mathbf{G}]_{\mathrm{GAS}}{ }^{+}$ion is not detected in the $t_{24 \mathrm{~h}}$ experiments. In the $t_{0 \mathrm{~h}}$ experiments the $[\mathbf{C} \cdot \mathrm{H} \cdot \mathbf{G}]_{\mathrm{ESI}}{ }^{+}$complexes represent $100 \%$ of the isolated ions, and just a minor amount of them undergo the gaseous interconversion $(16 \%-21 \%$ and $5.0 \%-6.0 \%$ for $\mathbf{B}$ $=\mathrm{EtNH}_{2}$ and $i \mathrm{PrNH}_{2}$, respectively). In the $t_{24 \mathrm{~h}}$ ion mixtures, the fraction of the $[\mathbf{C} \cdot \mathrm{H} \cdot \mathbf{G}]_{\mathrm{ESI}}{ }^{+}$species is at most $24 \%$ and $35 \%$ (B $=\mathrm{EtNH}_{2}$ and $i \mathrm{PrNH}_{2}$; Table 1). According to $t_{0 \mathrm{~h}}$ data, this means that the expected extent of $[\mathbf{C} \cdot \mathbf{H} \cdot \mathbf{G}]_{\mathrm{ESI}}{ }^{+} \rightarrow[\mathbf{C} \cdot \mathbf{H} \cdot \mathbf{G}]_{\mathrm{GAS}}{ }^{+}$ isomerization (i.e., the expected plateau) should not exceed $5 \%$

\section{Scheme 3. Formation of Three $[\mathrm{C} \cdot \mathrm{H} \cdot \mathrm{G}]^{+}$Aggregate Types}
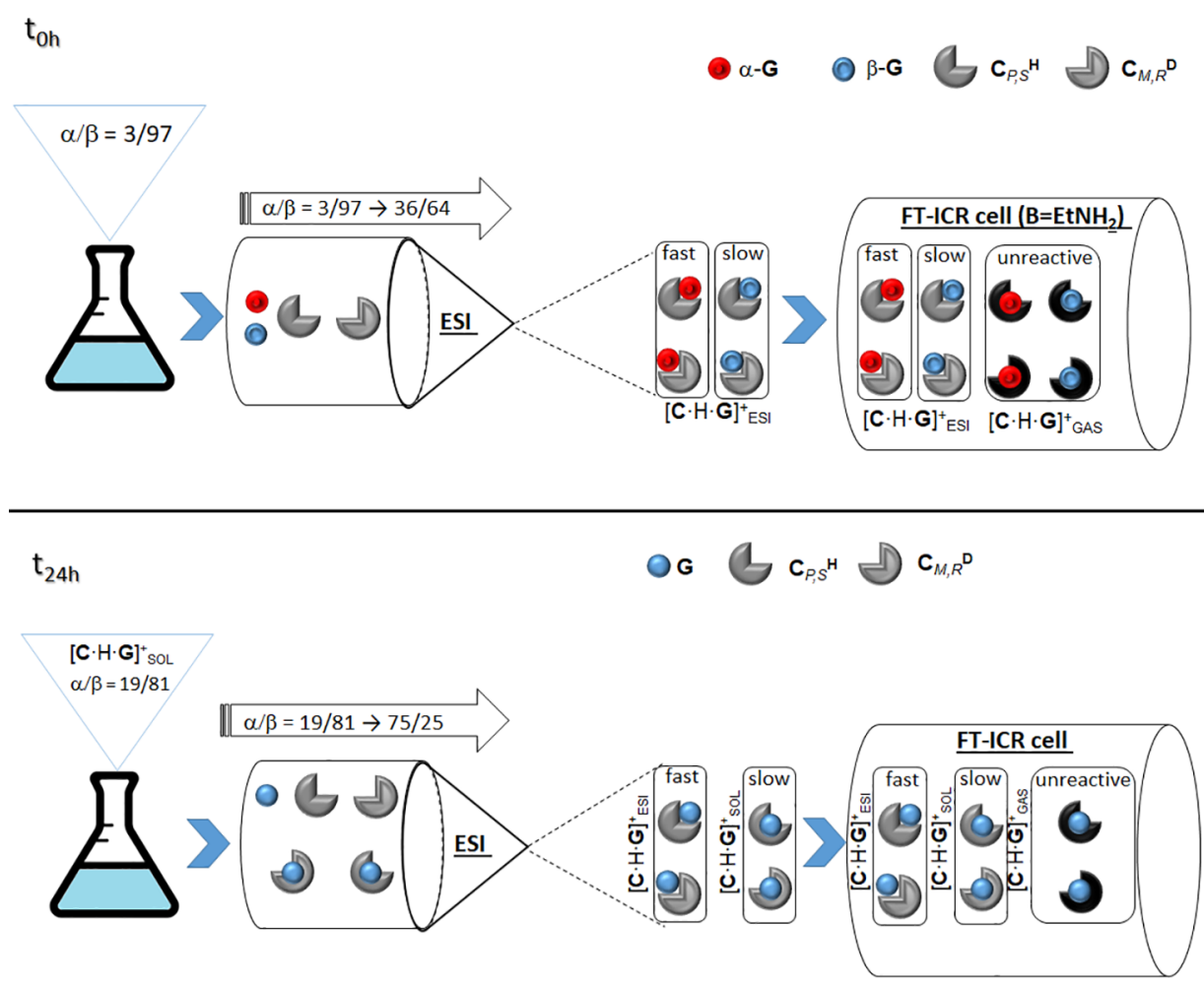
and $2 \%$ for $\mathbf{B}=\mathrm{EtNH}_{2}$ and $i \mathrm{PrNH}_{2}$, respectively, which is hardly detectable because of the superimposition of the very slow ligand exchange reaction (1) of the most abundant $[\mathbf{C} \cdot \mathrm{H}$. $\mathbf{G}]_{\mathrm{SOL}^{+}}{ }^{+}$species.

Summarizing, the occurrence of three $[\mathbf{C} \cdot \mathbf{H} \cdot \mathbf{G}]^{+}$isomeric species- $[\mathbf{C} \cdot \mathbf{H} \cdot \mathbf{G}]_{\mathrm{ESI}}{ }^{+}, \quad[\mathbf{C} \cdot \mathbf{H} \cdot \mathbf{G}]_{\mathrm{SOL}^{+}}{ }^{+}$, and $[\mathbf{C} \cdot \mathbf{H} \cdot \mathbf{G}]_{\mathrm{GAS}}{ }^{+}-\mathrm{can}$ be inferred from the present study (Scheme 3 ). $[\mathbf{C} \cdot \mathrm{H} \cdot \mathbf{G}]_{\mathrm{ESI}}{ }^{+}$, formed in the ESI source and corresponding to the fast-0 (allB), slow-0 ( $\left.\mathbf{B}=\mathrm{EtNH}_{2}\right)$, fast-24 (all-B) channels, is the most reactive one. $[\mathbf{C} \cdot \mathbf{H} \cdot \mathbf{G}]_{\mathrm{SOL}^{+}}$, formed from a solution complexation process that occurs in on an hours-long time scale and corresponding to the slow-24 (all-B) channel, exhibits a much lower reactivity. $[\mathbf{C} \cdot \mathrm{H} \cdot \mathbf{G}]_{\mathrm{GAS}}{ }^{+}$complexes, ascribed to the $t_{0 \mathrm{~h}}$ unreactive populations $\left(\mathbf{B}=\mathrm{EtNH}_{2}\right.$ and $\left.i \mathrm{PrNH}_{2}\right)$, arises from a $[\mathbf{C} \cdot \mathbf{H} \cdot \mathbf{G}]_{\mathrm{ESI}}{ }^{+} \rightarrow[\mathbf{C} \cdot \mathbf{H} \cdot \mathbf{G}]_{\mathrm{GAS}^{+}}$gas-phase isomerization.

What should the correlation of this multifaceted landscape with the coexistence of two interconverting anomers be? Given that the $\beta-\mathbf{G}$ anomer is more abundant in the freshly prepared solution, and slow- 0 is the predominant population (Table 1 , $t_{0 \mathrm{~h}}$ solution, $\mathbf{B}=\mathrm{EtNH}_{2}$ ), the slow- 0 and fast- 0 aggregates could be identified with the $\left[\mathbf{C}_{P, S}{ }^{\mathbf{H}} \cdot \mathbf{H} \cdot \beta-\mathbf{G}\right]_{\mathrm{ESI}}{ }^{+}$and $\left[\mathbf{C}_{P, S}{ }^{\mathbf{H}} \cdot \mathrm{H} \cdot \boldsymbol{\alpha}\right.$ $\mathbf{G}]_{\mathrm{ESI}}{ }^{+}$aggregates, respectively, or alternatively with the $\left[\mathrm{C}_{M, R} \mathrm{D}\right.$. $\mathrm{H} \cdot \beta-\mathbf{G}]_{\mathrm{ESI}}{ }^{+}$and $\left[\mathbf{C}_{M, R}{ }^{\mathrm{D}} \cdot \mathrm{H} \cdot \alpha-\mathbf{G}\right]_{\mathrm{ESI}}{ }^{+}$adducts (Scheme 3 , top). It is noteworthy that $[\mathbf{C} \cdot \mathrm{H} \cdot \beta-\mathbf{G}]_{\mathrm{ESI}}{ }^{+}$and $[\mathbf{C} \cdot \mathrm{H} \cdot \alpha-\mathbf{G}]_{\mathrm{ESI}}{ }^{+}$are not discriminated by the more basic $\mathbf{B}=i \mathrm{PrNH}_{2}$ and $s \mathrm{BuNH}_{2}$ (Figure 1, Tables S2,S3). If complexation during the ESI process took the snapshot of the present $\alpha / \beta$-ratio without any stereopreference, the $\left[\mathbf{C}_{P, S}{ }^{\mathbf{H}} \cdot \mathbf{H} \cdot \alpha-\mathbf{G}\right]^{+} /\left[\mathbf{C}_{P, S} \mathbf{H} \cdot \mathbf{H} \cdot \beta-\mathbf{G}\right]^{+}$and $\left[\mathbf{C}_{M, R}{ }^{\mathrm{D}} \cdot \mathrm{H} \cdot \alpha-\mathbf{G}\right]^{+} /\left[\mathbf{C}_{M, R} \mathbf{D} \cdot \mathbf{H} \cdot \beta-\mathbf{G}\right]^{+}$ratios (i.e., fast/slow ratio, $\left.\mathbf{B}=\mathrm{EtNH}_{2}\right)$ should be the same and correspond to the actual $\alpha / \beta$-ratio. In reality, the very different ratios reported in Table $1\left(\alpha / \beta=19 / 81\right.$ and $44 / 56$ for $\left[\mathbf{C}_{P, S}{ }^{\mathbf{H}} \cdot \mathbf{H} \cdot \mathbf{G}\right]^{+}$and $\left[\mathbf{C}_{M, R}{ }^{\mathbf{D}} \cdot \mathbf{H} \cdot\right.$ $\mathbf{G}]^{+}$, respectively) indicate that $\mathbf{C}_{M, R} \mathbf{D}$ is the more efficient hosting cavity for the $\alpha$-anomer, whose actual abundance in the free form ranges between $3 \%$ and $36 \% .{ }^{43}$ Finally, the Binduced isomerization of $[\mathbf{C} \cdot \mathrm{H} \cdot \mathbf{G}]_{\mathrm{ESI}}{ }^{+}$occurs with the same efficiency regardless of the $\mathbf{C}$ configuration $\left(\mathbf{B}=i \mathrm{PrNH}_{2}, k_{\text {iso }}\right.$ column in Table S2).

The anomeric discrimination is unfeasible in the $t_{24 \mathrm{~h}}$ experiments given that best fitting of the raw data can only discriminate between two populations that correspond to two different aggregate-types irrespective of the configuration of $\mathbf{G}$. Nevertheless, the host cyclochirality clearly affects the $[\mathrm{C} \cdot \mathrm{H}$. $\mathbf{G}]_{\mathrm{ESI}}{ }^{+} /[\mathbf{C} \cdot \mathbf{H} \cdot \mathbf{G}]_{\mathrm{SOL}^{+}}{ }^{+}$(i.e., fast/slow) ratio, which is invariably lower with the $\mathbf{C}_{M, R} \mathrm{D}$ receptor (Table $1, t_{24 \mathrm{~h}}$ solution). This effect suggests a higher thermodynamic stabilization achieved by $\left[\mathbf{C}_{M, R} \cdot \mathbf{D} \cdot \mathbf{G}\right]_{\mathrm{SOL}}{ }^{+}$with respect to the $\left[\mathbf{C}_{P, S}{ }^{\mathbf{H}} \cdot \mathbf{H} \cdot \mathbf{G}\right]_{\mathrm{SOL}}{ }^{+}$ diastereoisomer. The cyclochirality effect on the reaction efficiency is reported as $\rho$ values in Figure 2, wherein the dotted line $(\rho=1)$ indicates no enantioselectivity at all (for convenience, values measured for the reaction toward the $R$ enantiomer of $s \mathrm{BuNH}_{2}$ are reported, and the base chirality effect is discussed further below). In general, the $[\mathbf{C} \cdot \mathbf{H} \cdot \mathbf{G}]_{\mathrm{SOL}}{ }^{+}$ complexes exhibit an enantioselectivity above unity (full circles in Figure 2), indicating that the $\left[\mathbf{C}_{P, S}{ }^{\mathbf{H}} \cdot \mathbf{H} \cdot \mathbf{G}\right]_{\mathrm{SOL}}{ }^{+}$species reacts faster than $\left[\mathbf{C}_{M, R}{ }^{\mathbf{D}} \cdot \mathrm{H} \cdot \mathbf{G}\right]_{\mathrm{SOL}}{ }^{+}$. This chiral preference is reversed when the $[\mathbf{C} \cdot \mathbf{H} \cdot \mathbf{G}]_{\mathrm{ESI}}{ }^{+}$complexes are considered (empty squares and circles, full square in Figure 2). This opposite behavior agrees very well with the hypothesis of two reacting aggregate types, besides the "unreactive" $[\mathbf{C} \cdot \mathbf{H} \cdot \mathbf{G}]_{\mathrm{GAS}}{ }^{+}$. What can the structural difference among the three aggregate types be due to? After colliding with $\mathbf{B}$, a polar amino-sugar, which is engaged in $\mathrm{R}-\mathrm{NH}_{3}{ }^{+} \cdots \pi$ coordination in the center of the $\mathbf{C}$

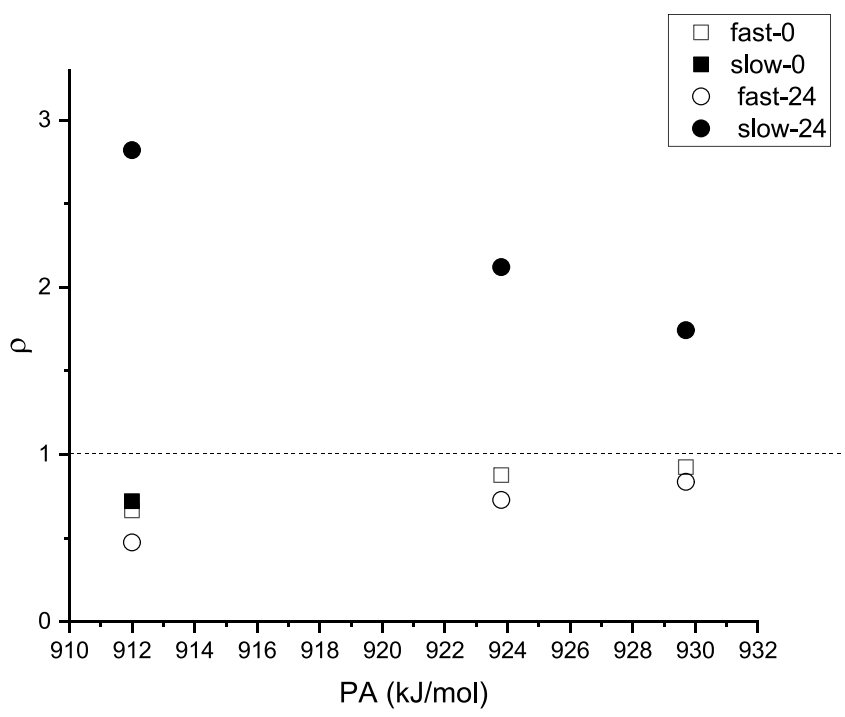

Figure 2. Enantioselectivity factor $\rho$ measured for the $\left[\mathbf{C}_{P, S}{ }^{\mathbf{H}} \cdot \mathbf{H} \cdot \mathbf{G}\right]^{+} /$ $\left[\mathbf{C}_{M, R} \text { D.H.G }\right]^{+}$pair vs the proton affinity of the neutral gas $\mathbf{B}$.

cavity in such a supramolecular architecture, ${ }^{38}$ probably interconverts to a better-suited conformer stabilized by tighter interactions. Indeed, the protonated $\mathbf{G}$ is kinetically trapped in the ESI-environment to form $[\mathbf{C} \cdot \mathbf{H} \cdot \mathbf{G}]_{\mathrm{ESI}}{ }^{+}$complexes that undergo a $\mathbf{B}$-induced isomerization of the amino-sugar conformation to generate a more stable $[\mathbf{C} \cdot \mathrm{H} \cdot \mathbf{G}]_{\mathrm{GAS}}{ }^{+}$species.

On the other side, the solvent-mediated formation of $[\mathbf{C} \cdot \mathrm{H} \cdot$ $\mathbf{G}]_{\mathrm{SOL}}{ }^{+}$could build up a noncovalent architecture looser than that of $[\mathbf{C} \cdot \mathbf{H} \cdot \mathbf{G}]_{\mathrm{GAS}}{ }^{+}$and still be poorly reactive toward the selected B. Computational work is planned to disentangle the structural differences of these aggregates.

A final consideration concerns the chirality effect of $s \mathrm{BuNH}_{2}$ on reactions 1 that are inferred from the relevant $\xi=k_{(R)} / k_{(S)}$ ratios reported in Table 2 . Taking into account the uncertainty accompanying the reported values, the measured $\xi$ values in most cases substantially diverge from unity, indicating a tight interaction between $\mathbf{B}$ and the chiral scaffold of the reacting complexes during the rate-determining step. In this frame, $\mathbf{B}$ should approach its proton-bound target frontside by

Table 2. Chirality Effect of $s \mathrm{BuNH}_{2}$ Expressed as the $\xi=$ $k_{(R)} / k_{(S)}$ Ratio

\begin{tabular}{|c|c|c|}
\hline \multicolumn{3}{|c|}{$t_{0 \mathrm{~h}}$ solution } \\
\hline host & population & $\xi$ \\
\hline $\mathbf{C}_{P, S}{ }^{\mathbf{H}}$ & fast -0 & $1.246 \pm 0.11$ \\
\hline $\mathrm{C}_{M, R} \mathbf{D}$ & fast- 0 & $1.230 \pm 0.11$ \\
\hline $\mathbf{C}_{P, S} \mathbf{D}$ & fast -0 & $1.185 \pm 0.10$ \\
\hline $\mathrm{C}_{M, R}{ }^{\mathrm{H}}$ & fast- 0 & $1.235 \pm 0.11$ \\
\hline \multicolumn{3}{|c|}{$t_{24 \mathrm{~h}}$ solution } \\
\hline host & population & $\xi$ \\
\hline $\mathbf{C}_{P, S}{ }^{\mathbf{H}}$ & fast-24 & $1.151 \pm 0.18$ \\
\hline $\mathbf{C}_{M, R} \mathbf{D}$ & fast-24 & $1.294 \pm 0.18$ \\
\hline $\mathbf{C}_{P, S}{ }^{\mathbf{H}}$ & slow-24 & $1.044 \pm 0.11$ \\
\hline $\mathbf{C}_{M, R} \mathbf{D}$ & slow-24 & $1.515 \pm 0.13$ \\
\hline $\mathbf{C}_{P, S}{ }^{\mathbf{D}}$ & fast-24 & $1.183 \pm 0.14$ \\
\hline $\mathrm{C}_{M, R}{ }^{\mathrm{H}}$ & fast-24 & $1.456 \pm 0.22$ \\
\hline $\mathbf{C}_{P, S}{ }^{\mathbf{D}}$ & slow-24 & $0.922 \pm 0.08$ \\
\hline $\mathrm{C}_{M, R} \mathbf{H}$ & slow-24 & $1.135 \pm 0.11$ \\
\hline
\end{tabular}


developing a tight interaction with the chiral upper rim of the host before releasing the neutral guest.

\section{CONCLUSION}

The coordination features of the cyclochiral resorcin[4]arene $\mathrm{C}$ were studied by running nano-ESI-FT-ICR ligand-exchange reactions of its complexes with unprotected protonated galactosamine $(\mathbf{G})$, which is known to undergo anomerization within the experimental time scale. The solution containing $\mathbf{C}$ and the protonated $\mathbf{G}$ was investigated right after its preparation as well as after $24 \mathrm{~h}$ to probe the aging effect on the kinetic features of the isolated $[\mathbf{C} \cdot \mathrm{H} \cdot \mathbf{G}]^{+}$species. The FTICR cell was loaded with different neutral gases (B) to study the effect of the $\mathbf{B}$ proton affinity on both the reaction efficiency and the kinetic pattern. The kinetic results point to the existence of three distinct supramolecular architectures irrespective of the configuration of $\mathbf{G}$, which differ in their origins and reactivity. The most reactive adducts $([\mathrm{C} \cdot \mathrm{H}$. G $\left.]_{\mathrm{ESI}}{ }^{+}\right)$are formed in the ESI ion source throughout the $\alpha \leftrightarrows \beta$ anomerization of $\mathbf{G}$, which is catalyzed in the ESI environment. The isolated $[\mathbf{C} \cdot \mathrm{H} \cdot \mathbf{G}]_{\mathrm{ESI}}{ }^{+}$complexes undergo a partial isomerization to the $[\mathbf{C} \cdot \mathbf{H} \cdot \mathbf{G}]_{\mathrm{GAS}}{ }^{+}$-type aggregate to achieve a greater stabilization of the supramolecular arrangement.

Given that the presence of long alkyl chains in the convex side of $\mathbf{C}$ induces any polar guest to be preferentially located on the concave side to establish $\mathrm{X}-\mathrm{H} \cdots \pi(\mathrm{X}=\mathrm{N}$ or $\mathrm{O})$ interactions, ${ }^{38}$ such a gas-phase isomerization is assumed to involve a $\mathbf{B}$-induced conformational rearrangement of $\mathbf{G}$ within the complex rather than its migration toward a different coordination site. The isomerization extent increases as $\mathrm{PA}_{\mathbf{B}}$ decreases, indicating that competition occurs between the ligand exchange, which is faster with the most basic $\mathbf{B}$, and the isomerization reactions. Finally, the $[\mathbf{C} \cdot \mathbf{H} \cdot \mathbf{G}]_{\mathrm{SOL}}{ }^{+}$adducts were unveiled in the experiments performed on the solutions aged for $24 \mathrm{~h}$; due to the very poor efficiency of their reaction, which was not observed in the freshly prepared mixture, $[\mathrm{C} \cdot \mathrm{H}$. $\mathbf{G}]_{\mathrm{SOL}}{ }^{+}$is necessarily generated in solution over a longer time scale.

The kinetic data discussed herein provide the first evidence of a supramolecular reorganization occurring inside a cyclochiral cavity, yielding alternative noncovalent networks that are different in the solution and gas phases. A cyclochirality effect was observed that strictly depends on the network of noncovalent interactions; the ESI native $\left[\mathbf{C}_{M, R}{ }^{\mathrm{D}} \cdot \mathrm{H} \cdot \mathrm{G}\right]_{\mathrm{ESI}}{ }^{+}$ion reacts faster than its $\left[\mathbf{C}_{P, S}{ }^{\mathbf{H}} \cdot \mathbf{H} \cdot \mathbf{G}\right]_{\mathrm{ESI}}{ }^{+}$quasi-diastereisomer, but this order is reversed in the corresponding $[\mathbf{C} \cdot \mathbf{H} \cdot \mathbf{G}]_{\mathrm{SOL}}{ }^{+}$-type complexes. Furthermore, $\mathbf{C}_{M, R} \mathbf{D}$ was found to trap $\alpha$ - $\mathbf{G}$ more effectively than $\beta-\mathbf{G}$ in the context of the $[\mathbf{C} \cdot \mathbf{H} \cdot \mathbf{G}]_{\mathrm{ESI}}{ }^{+}$ aggregate types. In other words, the $\left[\mathrm{C}_{M, R} \mathbf{D} \cdot \mathrm{H} \cdot \alpha-\mathbf{G}\right]_{\mathrm{ESI}}{ }^{+}>$ $\left[\mathbf{C}_{M, R} \cdot \mathbf{D} \cdot \beta-\mathbf{G}\right]_{\mathrm{ESI}}{ }^{+}$stereo preference ranking was assessed. On the other side, although no $\alpha / \beta$ discrimination could be detected in the $t_{24 \mathrm{~h}}$ experiments, the $\mathrm{C}_{M, R}{ }^{\mathrm{D}}$ receptor was shown to more effectively stabilize the $[\mathbf{C} \cdot \mathrm{H} \cdot \mathbf{G}]_{\mathrm{SOL}}{ }^{+}$complexes than its $\mathbf{C}_{P, S}{ }^{\mathbf{H}}$ enantiomer.

\section{ASSOCIATED CONTENT}

\section{SI Supporting Information}

The Supporting Information is available free of charge at https://pubs.acs.org/doi/10.1021/jasms.0c00437.

Exponential and logarithmic depletion curves of the isolated aggregates toward the neutral gases $\mathbf{B}$; reaction efficiency percentages; and tables reporting measured rate constants, KIE, and population distributions (PDF)

\section{AUTHOR INFORMATION}

\section{Corresponding Author}

Caterina Fraschetti - Dipartimento di Chimica e Tecnologie del Farmaco, Sapienza-Università di Roma, I-00185 Rome, Italy; (1) orcid.org/0000-0002-5095-5388;

Email: caterina.fraschetti@uniroma1.it

\section{Authors}

Matthias C. Letzel - Organisch-Chemisches Institut der Westf. Wilhelms Abt. Massenspektrometrie, Westfälische WilhelmsUniversität Münster, 48149 Münster, Germany

Marlene Paletta - Department of Chemistry, Bielefeld University, D-33501 Bielefeld, Germany

Jochen Mattay - Department of Chemistry, Bielefeld University, D-33501 Bielefeld, Germany

Maria Elisa Crestoni - Dipartimento di Chimica e Tecnologie del Farmaco, Sapienza-Università di Roma, I-00185 Rome, Italy; (ㅇ) orcid.org/0000-0002-0991-5034

Barbara Chiavarino - Dipartimento di Chimica e Tecnologie del Farmaco, Sapienza-Università di Roma, I-00185 Rome, Italy; 이잉.org/0000-0002-1585-7061

Antonello Filippi - Dipartimento di Chimica e Tecnologie del Farmaco, Sapienza-Università di Roma, I-00185 Rome, Italy

Complete contact information is available at:

https://pubs.acs.org/10.1021/jasms.0c00437

\section{Notes}

The authors declare no competing financial interest.

\section{REFERENCES}

(1) Kolesnichenko, I. V.; Anslyn, E. V. Practical applications of supramolecular chemistry. Chem. Soc. Rev. 2017, 46 (9), 2385-2390.

(2) Rey-Rico, A.; Cucchiarini, M. Supramolecular CyclodextrinBased Hydrogels for Controlled Gene Delivery. Polymers 2019, 11 (3), 514-523.

(3) Song, N.; Lou, X. Y.; Ma, L.; Gao, H.; Yang, Y. W. Supramolecular nanotheranostics based on pillarenes. Theranostics 2019, 9 (11), 3075-3093.

(4) Chen, Y.; Sun, Z. Supramolecular Chemotherapy Based on the Host-Guest Complex of Lobaplatin-Cucurbit[7]uril. ACS Applied Bio Materials 2020, 3 (4), 2449-2454.

(5) Mao, W.; Liao, Y.; Ma, D. A supramolecular assembly mediated by host-guest interactions for improved chemo-photodynamic combination therapy. Chem. Commun. 2020, 56 (30), 4192-4195.

(6) Cheng, C. C.; Sun, Y. T.; Lee, A. W.; Huang, S. Y.; Fan, W. L.; Chiao, Y. H.; Chiu, C. W.; Lai, J. Y. Hydrogen-bonded supramolecular micelle-mediated drug delivery enhances the efficacy and safety of cancer chemotherapy. Polym. Chem. 2020, 11 (26), 27912798.

(7) Legnani, L.; Puglisi, R.; Pappalardo, A.; Chiacchio, M. A.; Trusso Sfrazzetto, G. Supramolecular recognition of phosphocholine by an enzyme-like cavitand receptor. Chem. Commun. 2020, 56 (4), 539542.

(8) Yan, F.; Chen, F.; Wu, X. H.; Luo, J.; Zhou, X. S.; Horsley, J. R.; Abell, A. D.; Yu, J.; Jin, S.; Mao, B. W. Unique Metal Cation Recognition via Crown Ether-Derivatized Oligo(phenyleneethynylene) Molecular Junction. J. Phys. Chem. C 2020, 124 (16), 8496-8503.

(9) Li, Y.; Hu, X.; Song, X.; Hou, Y.; Guo, Q. Removal of potentially toxic metals from soil by para-sulphonato-thiacalix[4]arene: competitive extraction and selectivity sequence. RSC $A d v$. 2015, 5 (92), $75033-75043$. 
(10) Werner, E. J.; Biros, S. M. Supramolecular ligands for the extraction of lanthanide and actinide ions. Org. Chem. Front. 2019, 6 (12), 2067-2094.

(11) Jagleniec, D.; Dobrzycki, L.; Karbarz, M.; Romanski, J. Ion-pair induced supramolecular assembly formation for selective extraction and sensing of potassium sulfate. Chem. Sci. 2019, 10 (41), 95429547.

(12) Filippi, A.; Crestoni, M. E.; Fraschetti, C.; Montagna, M.; Guarcini, L.; Marcantoni, E.; Glucini, M.; Speranza, M. Reactivity of contact ion pairs in a charged monotopic receptor. Int. J. Mass Spectrom. 2017, 418, 198-203.

(13) Gale, P. A.; Howe, E. N. W.; Wu, X.; Spooner, M. J. Anion receptor chemistry: Highlights from 2016. Coord. Chem. Rev. 2018, $375,333-372$.

(14) Zhao, J.; Yang, D.; Yang, X. J.; Wu, B. Anion coordination chemistry: From recognition to supramolecular assembly. Coord. Chem. Rev. 2019, 378, 415-444.

(15) Chen, L.; Berry, S. N.; Wu, X.; Howe, E. N. W.; Gale, P. A. Advances in Anion Receptor Chemistry. Chem. 2020, 6 (1), 61-141.

(16) Hein, R.; Beer, P. D.; Davis, J. J. Electrochemical Anion Sensing: Supramolecular Approaches. Chem. Rev. 2020, 120 (3), $1888-1935$.

(17) Hayashi, T.; Ohishi, Y.; Abe, H.; Inouye, M. Preferential Recognition and Extraction to Pentoses over Hexoses by a D6hSymmetrical Ethynylphenol Macrocycle with Six Inner Phenolic Hydroxy Groups. J. Org. Chem. 2020, 85 (4), 1927-1934.

(18) Mateus, P.; Chandramouli, N.; Mackereth, C. D.; Kauffmann, B.; Ferrand, Y.; Huc, I. Allosteric Recognition of Homomeric and Heteromeric Pairs of Monosaccharides by a Foldamer Capsule. Angew. Chem., Int. Ed. 2020, 59 (14), 5797-5805.

(19) Francesconi, O.; Martinucci, M.; Badii, L.; Nativi, C.; Roelens, S. A Biomimetic Synthetic Receptor Selectively Recognising Fucose in Water. Chem. - Eur. J. 2018, 24 (26), 6828-6836.

(20) Gunasekara, R. W.; Zhao, Y. A General Method for Selective Recognition of Monosaccharides and Oligosaccharides in Water. $J$. Am. Chem. Soc. 2017, 139 (2), 829-835.

(21) Francesconi, O.; Cicero, F.; Nativi, C.; Roelens, S. A Preorganized Hydrogen-Bonding Motif for the Molecular Recognition of Carbohydrates. ChemPhysChem 2020, 21 (3), 257-262.

(22) Ohishi, Y.; Abe, H.; Inouye, M. Saccharide Recognition and Helix Formation in Water with an Amphiphilic Pyridine-Phenol Alternating Oligomer. Eur. J. Org. Chem. 2017, 2017 (46), 69756979.

(23) Jang, Y.; Natarajan, R.; Ko, Y. H.; Kim, K. Cucurbit[7]uril: A High-Affinity Host for Encapsulation of Amino Saccharides and Supramolecular Stabilization of Their $\alpha$-Anomers in Water. Angew. Chem., Int. Ed. 2014, 53 (4), 1003-1007.

(24) Lee, H. H. L.; Kim, H. I. Supramolecular Analysis of Monosaccharide Derivatives Using Cucurbit[7]uril and Electrospray Ionization Tandem Mass Spectrometry. Isr. J. Chem. 2018, 58 (3-4), 472-478.

(25) Wang, J.; Jang, Y.; Khedkar, J. K.; Koo, J. Y.; Kim, Y.; Lee, C. J.; Rhee, Y. M.; Kim, K. How Does Solvation Affect the Binding of Hydrophilic Amino Saccharides to Cucurbit[7]uril with Exceptional Anomeric Selectivity? Chem. - Eur. J. 2016, 22 (44), 15791-15799.

(26) Fraschetti, C.; Filippi, A.; Crestoni, M. E.; Ema, T.; Speranza, M. Multifunctional Macrocyclic Receptors as Templates for Aromatic Amino Acids: A Rare Example of a Highly Selective Multi-Input Multi-Output Chemo-"Logic Gate. ChemPlusChem 2013, 78 (9), 979-987.

(27) Fraschetti, C.; Filippi, A.; Crestoni, M. E.; Villani, C.; Roselli, G.; Mortera, S. L.; Speranza, M. Enantioselective supramolecular carriers for nucleoside drugs. A thermodynamic and kinetic gas phase investigation. J. Am. Soc. Mass Spectrom. 2012, 23 (10), 1778-1785.

(28) Fraschetti, C.; Letzel, M. C.; Filippi, A.; Speranza, M.; Mattay, J. Enantioselective supramolecular devices in the gas phase. Resorcin[4]arene as a model system. Beilstein J. Org. Chem. 2012, 8, 539-550.
(29) Kodiah Beyeh, N.; Göth, M.; Kaufmann, L.; Schalley, C. A.; Rissanen, K. The Synergetic Interplay of Weak Interactions in the Ion-Pair Recognition of Quaternary and Diquaternary Ammonium Salts by Halogenated Resorcinarenes. Eur. J. Org. Chem. 2014, 2014 (1), 80-85.

(30) Li, N.; Harrison, R. G.; Lamb, J. D. Application of resorcinarene derivatives in chemical separations. J. Inclusion Phenom. Macrocyclic Chem. 2014, 78 (1-4), 39-60.

(31) Beyeh, N. L.; Pan, F.; Valkonen, A.; Rissanen, K. Encapsulation of secondary and tertiary ammonium salts by resorcinarenes and pyrogallarenes: the effect of size and charge concentration. CrystEngComm 2015, 17 (5), 1182-1188.

(32) Ruiz-Botella, S.; Vidossich, P.; Ujaque, G.; Vicent, C.; Peris, E. A Tetraferrocenyl-Resorcinarene Cavitand as a Redox-Switchable Host of Ammonium Salts. Chem. - Eur. J. 2015, 21 (29), 1055810565

(33) Beyeh, N. K.; Pan, F.; Bhowmik, S.; Mäkelä, T.; Ras, R. H. A.; Rissanen, K. N-Alkyl Ammonium Resorcinarene Salts as High-Affinity Tetravalent Chloride Receptors. Chem. - Eur. J. 2016, 22 (4), 13551361.

(34) D'Acquarica, I.; Ghirga, F.; Quaglio, D.; Cerreto, A.; Ingallina, C.; Tafi, A.; Botta, B. Molecular Recognition of Natural Products by Resorc[4]arene Receptors. Curr. Pharm. Des. 2016, 22 (12), 17151729.

(35) Fraschetti, C.; Montagna, M.; Crestoni, M. E.; Calcaterra, A.; Aiello, F.; Santi, L.; Filippi, A. Kinetic enantioselectivity of a protonated bis(diamido)-bridged basket resorcin[4]arene towards alanine peptides. Org. Biomol. Chem. 2017, 15 (5), 1183-1189.

(36) Botta, B.; Fraschetti, C.; D’Acquarica, I.; Sacco, F.; Mattay, J.; Letzel, M. C.; Speranza, M. Unprecedented gas-phase chiroselective logic gates. Org. Biomol. Chem. 2011, 9 (6), 1717-1719.

(37) Filippi, A.; Fraschetti, C.; Piccirillo, S.; Rondino, F.; Botta, B.; D'Acquarica, I.; Calcaterra, A.; Speranza, M. Chirality Effects on the IRMPD Spectra of Basket Resorcinarene/Nucleoside Complexes. Chem. - Eur. J. 2012, 18 (27), 8320-8328.

(38) Fraschetti, C.; Letzel, M. C.; Paletta, M.; Mattay, J.; Speranza, M.; Filippi, A.; Aschi, M.; Rozhenko, A. B. Cyclochiral resorcin[4]arenes as effective enantioselectors in the gas phase. J. Mass Spectrom. 2012, 47 (1), 72-78.

(39) Sawada, M. Chiral Recognition in Host-Guest Complexation Determined by FAB Mass Spectrometry. J. Mass Spectrom. Soc. Jpn. 1997, 45 (3), 439-458.

(40) U.S. Department of Commerce, National Institute of Standards and Technology. NIST Chemistry WebBook, SRD 69. http://webbook. nist.gov.

(41) Su, T.; Chesnavich, W. J. Parametrization of the ion-polar molecule collision rate constant by trajectory calculations. J. Chem. Phys. 1982, 76 (10), 5183-5185.

(42) Su, T. Erratum: Trajectory calculations of ion-polar molecule capture rate constants at low temperatures [J. Chem. Phys. 88, 4102 (1988)]. J. Chem. Phys. 1988, 89 (8), 5355.

(43) Fraschetti, C.; Guarcini, L.; Zazza, C.; Mannina, L.; Circi, S.; Piccirillo, S.; Chiavarino, B.; Filippi, A. Real time evolution of unprotected protonated galactosamine probed by IRMPD spectroscopy. Phys. Chem. Chem. Phys. 2018, 20 (13), 8737-8743. 